\title{
Bearing capacity calculation of reinforced concrete corbels under the shear action
}

\author{
Oksana Dovzhenko ${ }^{1,}$, Volodymyr Pohribnyi ${ }^{1}$, Volodymyr Pents $^{1}$, and Dmytro Mariukha ${ }^{1}$ \\ ${ }^{1}$ Poltava National Technical Yuri Kondratyuk University, Pershotravneviy sq., 24, Poltava, 36011, \\ Ukraine
}

\begin{abstract}
The necessity of creating a general methodology for concrete and reinforced concrete elements strength calculation under the shear is established. Three failure cases of reinforced concrete corbels under the shear are considered. The solutions of problems of corbels strength with failure along the whole section, close to the normal, in the compressed zone under an inclined crack and within the compressed inclined strip are given. A variational method in the plasticity theory, the virtual velocities principle and the characteristic lines method are used for concrete and reinforced concrete elements calculations. In the ultimate state, concrete is considered as a rigid-plastic body. The shear is realized in case when the plastic deformation is localized in the compressed zone. The calculating ultimate load results for different failure cases are given. Such a design scheme is implemented, in which the console strength is minimal. This corresponds to the minimum of power of plastic deformation in concrete compressed zone. Reinforced concrete corbels calculation engineering methods are offered. The elements obtaining effective constructive decisions direction based on the plasticity theory use is determined.
\end{abstract}

\section{Introduction}

Concrete and reinforced concrete elements that work on the perception of joint action of transverse forces and bending moments are widely used in practice. These include the beam and slab elements supporting areas, column corbels, T-beams and I-beams flanges, base plates cantilevered parts, pile grillage, double-girder columns lintels and other structures. The reinforced concrete supporting corbels are used in the railway transport structures for the superstructure support.

An important task is to increase the efficiency of their work and reduce the material consumption of constructive solutions used in the construction, reconstruction and structures restoration. One of the components in this direction is the methods for calculating bearing capacity improvement.

Research articles [1-4] are devoted to the strength problem of reinforced concrete corbels. The ultimate stress-strain state is investigated, experimental data are presented and their calculation methods analysis is performed in these articles. Existing calculation methods have a significant number of disadvantages, namely: the elasticity theory methods

* Corresponding author: o.o.dovzhenko@gmail.com 
do not correspond to the elements actual work in the ultimate state; the empirical approach is cumbersome, the obtained results are influenced by the experimental conditions, it is not always possible to take into account the full number of determinants; frame-core model does not consider all possible cases of failure at the various geometric parameters of elements, loading conditions, reinforcement, etc.

\section{Unsolved part of the problem}

The creation of general methodology for calculating bearing capacity of reinforced concrete corbels is an urgent task. This methodology should cover various failure forms, determine their implementation boundaries, take into account the operation specifics in the ultimate state, allow to obtain constructive solutions with optimal longitudinal and transverse elements reinforcement equal to the normal and inclined sections, and allow to reduce material capacity of structures and to exclude cases of strength revaluation.

The specificity of work of these elements lies in the fact that fields, strips, intense strains and stresses concentration lines are formed in the power flows action direction [5, 6], the which presence is confirmed by experimental research [7-9]. Their placement is determined by the external forces and supporting reactions of the place of application. The plastic deformation concentration and the biaxial compression zones presence permits to use the variational method of concrete plasticity theory $[10,11]$ and the method of characteristics [12] as the general methodology basis for calculating the concrete and reinforced concrete elements bearing capacity.

The work purpose is to improve the methods for calculating the reinforced concrete corbels bearing capacity under the shear on the unified approach basis with the plasticity theory use.

\section{Calculating methods for corbels based on the plasticity theory}

In this paper, three failure cases of reinforced concrete corbels under shear are considered: for an integral section close to the normal, in a compressed zone under an inclined crack and for a sloping compressed strip.

In case of $a / h \leq 0.15$ and shear spans $c / h \leq 0.3$, simultaneous failure of the reinforced concrete corbel in the compression and tension areas is observed - failure along the whole cross-section (Fig. 1 a). In this case, the concrete plastic deformation is localized in a compressed zone in a thin layer on the displacement surface, and the stress in the tensile zone reaches the tensile strength values.

With the increase of parameter $a / h$ and the impact of bending moment, the stress level of relative limit values in the tensile zone of corbel is ahead the stress level in the compressed zone. First a crack appears near the edge of the loading platform, which is close to the corbel fixed and. It grows and at a transverse reinforcement slight intensity and yield point stresses in the reinforcement, a compressed concrete zone shear is realized (Fig. 1 b).

In the case of a strong transverse reinforcement sufficient to prevent the first crack development, and with the $c / h$ that are short corbels characteristic, a second crack emerges that extends from the outer facet of the loading platform to the corbel lower corner. There is a compressed inclined strip and a shear within the strip is implemented (Fig. $1 \mathrm{c}$ ).

To determine the reinforced concrete corbels bearing capacity, the kinematic schemes and the stresses distribution on the failure surface along the whole section (Fig. 2 a) are considered. The strength problem of concrete wedges, which simulate the compressed zone under an inclined crack (Fig. 2 b), and the strength problem of compressed inclined strip (Fig. 2 c) are solved. 


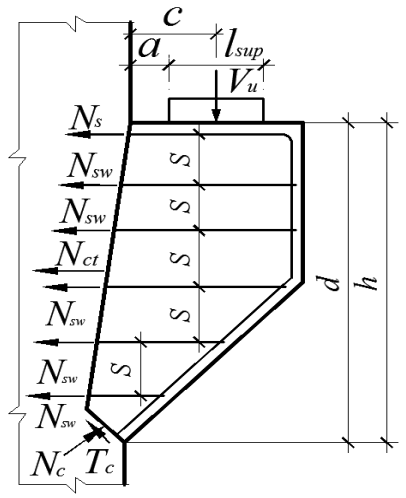

a)

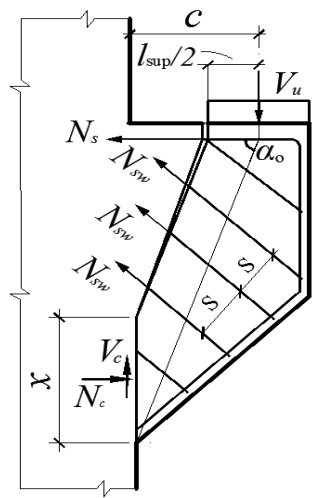

b)

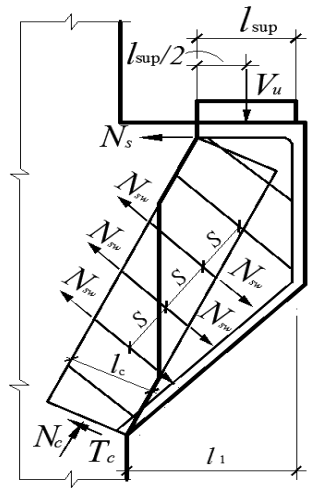

c)

Fig. 1. Design scheme of reinforced concrete corbel: a) with failure for whole section; b) with compressed zone under inclined crack shear; c) with compressed strip shear.

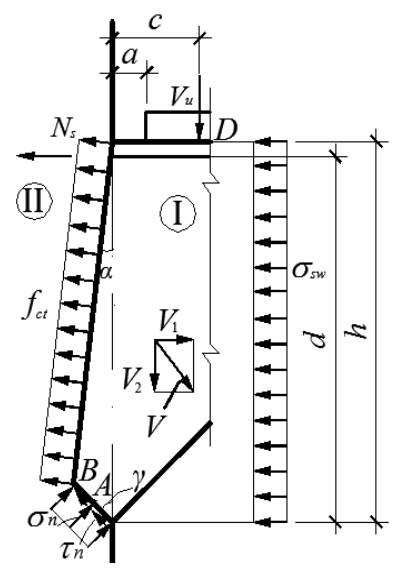

a)

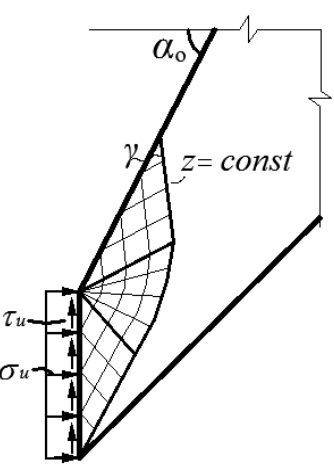

c)

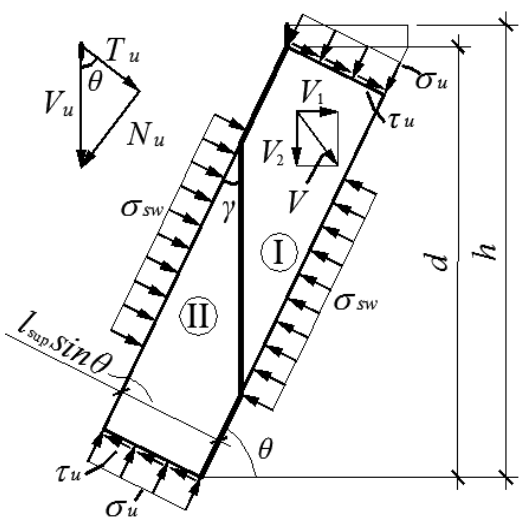

Fig. 2. For calculating the reinforced concrete corbels strength: a) with whole section failure; b) with compressed concrete wedge under an inclined crack shear; c) with shear within the compressed inclined strip.

A variational method is used in the plasticity theory and functional of principle of virtual velocities [5], which, in the inertial and mass forces absence, has the form

$$
J=\int_{S_{l}}\left(W_{c}+W_{s}\right) d S-\int_{S_{f}} f_{i}^{*} V_{i} d S
$$

where $W_{c}$ and $W_{s}$ - concrete and reinforcement deformation power; $S_{l}$ - failure surface; $S_{f}-$ surface on which the forces (stresses) $f_{i}^{*}$ are given at velocities $V_{i}$. The reinforcement effect is considered as a pre-stressing.

The functional is investigated for the stationary state using the equation $\delta J=0$. Parameter $k=V_{1} / V_{2}$ is varied in the orthogonal directions and the inclination angles of areas of failure surface $\alpha$ and $\gamma: \partial k / \partial V_{u}, \partial \operatorname{tg} \alpha / \partial V_{u}$ and $\partial \operatorname{tg} \gamma / \partial V_{u}[13,14]$. BalandinGeniev condition for the concrete strength $[12,15]$ is accepted. The failure occurs by moving one rigid disk I to another II (Fig. 2 a, b). The ultimate load magnitude corresponds to the deformation power minimum, taking into account the reinforcement work. 
By the failure along the whole cross-section, the relative transverse force that the reinforcement concrete corbel perceives is determined by the formula

$$
\frac{V_{u}}{f_{c} b h}=\frac{\left[\sqrt{\left(1-\chi+\chi^{2}\right) / 3} \sqrt{4(k-\operatorname{tg} \gamma)^{2}+(1+k \operatorname{tg} \gamma)^{2}}-(1-\chi)(k-\operatorname{tg} \gamma)\right] \operatorname{tg} \alpha+\chi \operatorname{tg} \gamma(k+\operatorname{tg} \alpha)}{\operatorname{tg} \alpha+\operatorname{tg} \gamma}+
$$

where $\chi=f_{c t} / f_{c} ; \sigma_{s}=\rho_{f} f_{y}$, here $\rho_{f}=\frac{A_{s}}{b h} ; \sigma_{s w}=\rho_{w} f_{y}, \rho_{w}=\frac{A_{s w}}{b s}$,

when applying equilibrium equations

$$
\sum M_{A}=0 ; \sum M_{B}=0 ; \sum M_{D}=0 .
$$

Normal and tangential stresses that act on the failure surface compressed section and are used in equilibrium equations, are equal to

$$
\begin{aligned}
& \frac{\tau_{n}}{f_{c}}= \pm \frac{\sqrt{\left(1-\chi+\chi^{2}\right) / 3}(1+k \operatorname{tg} \gamma)}{2 \sqrt{(k-\operatorname{tg} \gamma)^{2}+0.25(1+k \operatorname{tg} \gamma)^{2}}}, \\
& \frac{\sigma_{n}}{f_{c}}=1-\chi-\frac{2 \sqrt{\left(1-\chi+\chi^{2}\right) / 3}(k-\operatorname{tg} \gamma)}{\sqrt{(k-\operatorname{tg} \gamma)^{2}+0.25(1+k \operatorname{tg} \gamma)^{2}}} .
\end{aligned}
$$

The obtained results in solving the problems of corbel strength in the failure case in the

\begin{tabular}{|c|c|c|c|c|c|c|c|c|c|c|}
\hline \multirow{5}{*}{$\frac{f_{c t}}{f_{c}}$} & \multirow{5}{*}{$\rho_{s} \frac{f_{y}}{f_{c}}$} & \multicolumn{9}{|c|}{$\frac{V_{u}}{f_{c} b h}$ by } \\
\hline & & \multicolumn{9}{|c|}{$c / h$} \\
\hline & & \multicolumn{3}{|c|}{0.15} & \multicolumn{3}{|c|}{0.2} & \multicolumn{3}{|c|}{0.25} \\
\hline & & \multicolumn{9}{|c|}{$\sigma_{s w}=\rho_{w} f_{y} / f_{c}$} \\
\hline & & 0.025 & 0.05 & 0.075 & 0.025 & 0.05 & 0.075 & 0.025 & 0.05 & 0.075 \\
\hline \multirow{3}{*}{0.05} & 0.075 & 0.353 & 0.375 & 0.395 & 0.314 & 0.335 & 0.349 & 0.281 & 0.301 & 0.319 \\
\hline & 0.1 & 0.4 & 0.42 & 0.438 & 0.359 & 0.378 & 0.395 & 0.324 & 0.342 & 0.358 \\
\hline & 0.125 & 0.443 & 0.46 & 0.476 & 0.401 & 0.417 & 0.433 & 0.364 & 0.38 & 0.394 \\
\hline \multirow{3}{*}{0.1} & 0.075 & 0.394 & 0.412 & 0.429 & 0.353 & 0.371 & 0.387 & 0.318 & 0.335 & 0.351 \\
\hline & 0.1 & 0.435 & 0.452 & 0.467 & 0.393 & 0.409 & 0.423 & 0.357 & 0.372 & 0.386 \\
\hline & 0.125 & 0.474 & 0.488 & 0.502 & 0.431 & 0.445 & 0.457 & 0.393 & 0.406 & 0.418 \\
\hline \multirow{3}{*}{0.15} & 0.075 & 0.427 & 0.442 & 0.456 & 0.385 & 0.4 & 0.413 & 0.349 & 0.363 & 0.376 \\
\hline & 0.1 & 0.464 & 0.478 & 0.49 & 0.422 & 0.435 & 0.447 & 0.384 & 0.367 & 0.408 \\
\hline & 0.125 & 0.499 & 0.511 & 0.522 & 0.455 & 0.467 & 0.478 & 0.417 & 0.428 & 0.438 \\
\hline
\end{tabular}
whole section are shown in Table 1.

Table 1. Ultimate value of relative transverse force that is perceived by the corbel under the shear across the whole cross-section.

Unknown variables of strength problem when shearing a compressed zone under an inclined crack: $V_{u}, N_{c}, V_{c}, N_{s}, x$. 

Equation
1) $\sum X=0$
2) $\sum Y=0$;
3) $\sum M=0$;
4) $x=0,5 l_{\text {sup }} d / c$;
5) $V_{c}=\varphi_{1} f_{c} b x+\varphi_{2} N_{c}$,

where $\varphi_{1}$ and $\varphi_{2}$ are parameters that depend on the concrete class and the ratio $d / c$.

The truncated wedge strength can be estimated by the method of characteristic lines [13]. Using the known uniaxial compression stress state in the plasticity triangular area near the facet, formed by an inclined crack, the characteristics properties $\mathrm{z}=$ const, force dependence (6) between $V_{c}$ and $N_{c}$ on the truncated facet is obtained.

In the case of application of virtual velocities principle $[10,16]$, the dependence (6) has the following form

$$
N_{c}=\frac{f_{c} b x\left[\sqrt{\left(1-\chi+\chi^{2}\right) / 3} \sqrt{4(k-\operatorname{tg} \gamma)^{2}+(1+k \operatorname{tg} \gamma)^{2}}-(1-\chi)(k-\operatorname{tg} \gamma)\right]\left[1+\operatorname{tg} \alpha_{\mathrm{o}} /\left(\operatorname{tg} \gamma-\operatorname{tg} \alpha_{\mathrm{o}}\right)\right]}{\operatorname{tg} \gamma}-k V_{c} .
$$

The forces ultimate values that are perceived by the compressed zone concrete wedges, are given in Table 2 .

Table 2. Ultimate value of relative transverse and longitudinal forces that are perceived by concrete wedges at $\alpha_{\mathrm{o}}=45^{\circ}$ and $f_{c t} / f_{c}=0.1$.

\begin{tabular}{|c|c|c|c|c|c|c|c|c|}
\hline \multirow{2}{*}{ Relative efforts } & \multicolumn{7}{|c|}{ Loading direction angle $\beta=\operatorname{arctg} \tau_{n} / \sigma_{n}{ }^{\circ}$} \\
\cline { 2 - 9 } & 10 & 15 & 20 & 25 & 30 & 35 & 40 & 45 \\
\hline$\frac{N_{c}}{f_{c} b x}$ & 1.8 & 1.5 & 1.27 & 1.05 & 0.887 & 0.737 & 0.615 & 0.516 \\
\hline$\frac{V_{c}}{f_{c} b x}$ & 0.317 & 0.403 & 0.461 & 0.495 & 0.512 & 0.515 & 0.516 & 0.516 \\
\hline
\end{tabular}

Unknown variables of strength problem under the shear in the inclined strip: $V_{u}, N_{c}, T_{c}$. Equation:

$$
\text { 1) } \tau_{u}=\frac{T_{c}-N_{s} \sin \theta}{b l_{c}}=\frac{T_{c}}{b l_{c}}-\frac{A_{s} E_{s}}{b l_{\text {sup }} E_{c}} f_{c} \text {, }
$$

where $T_{c}=\tau_{n} b l_{c}=\left\{\frac{f_{c}\left[\sqrt{\left(1-\chi+\chi^{2}\right) / 3} \sqrt{4(k-\operatorname{tg} \gamma)^{2}+(1+k \operatorname{tg} \gamma)^{2}}-(1-\chi)(k-\operatorname{tg} \gamma)\right]+k \sigma_{s w}}{(\operatorname{tg} \theta+k) \operatorname{tg} \gamma}\right\} b l_{c}$;

2) $N_{c}=\sigma_{u} b l_{c}=\left\{\frac{f_{c}\left[\sqrt{\left(1-\chi+\chi^{2}\right) / 3} \sqrt{4(k-\operatorname{tg} \gamma)^{2}+(1+k \operatorname{tg} \gamma)^{2}}-(1-\chi)(k-\operatorname{tg} \gamma)\right]+k \sigma_{s w}}{\operatorname{tg} \gamma}-k \tau_{n}\right\} b l_{c}$

3) $V_{u}=N_{c} l_{\text {sup }} / l_{c}$. 
The ultimate values of forces that are perceived by the inclined compressed element are given in Table 3.

Of the above kinematic schemes of failure, the one in which the bearing of corbel is minimal is implemented.

Table 3. Relative effort ultimate value perceived by reinforced concrete corbel under the shear by inclined strip.

\begin{tabular}{|c|c|c|c|c|c|c|c|c|c|c|}
\hline \multirow{3}{*}{$\frac{f_{c t}}{f_{c}}$} & \multirow{3}{*}{$\frac{\sigma_{s w}}{f_{c}}=\frac{\rho_{w} d E_{s w}}{l_{c} E_{c}}$} & \multicolumn{9}{|c|}{$\frac{V_{u}}{f_{c} b l_{\text {sup }}}$ by } \\
\hline & & \multicolumn{9}{|c|}{ Loading direction angle $\beta=\operatorname{arctg} \tau_{n} / \sigma_{n},{ }^{o}$} \\
\hline & & 5 & 10 & 15 & 20 & 25 & 30 & 35 & 40 & 45 \\
\hline \multirow{3}{*}{0.1} & 0.05 & 0.969 & 0.866 & 0.771 & 0.684 & 0.605 & 0.532 & 0.464 & 0.403 & 0.346 \\
\hline & 0.1 & 1.04 & 0.933 & 0.834 & 0.742 & 0.657 & 0.578 & 0.505 & 0.437 & 0.375 \\
\hline & 0.15 & 1.11 & 0.995 & 0.891 & 0.794 & 0.704 & 0.62 & 0.541 & 0.468 & 0.401 \\
\hline
\end{tabular}

The engineering calculation of bearing capacity of reinforced concrete corbels is proposed to be carried out using formulas (11) and (12), based on the results of solving the strength problems of the truncated wedge and the compressed inclined strip.

Output data for solving the problems of bearing capacity of reinforced concrete corbels: loading area length $l_{\text {sup; }}$; distance from the column facet to the force application place $c$; width, height, working height and corbel span $b, h, d, l_{1}$; concrete class $\mathrm{C}\left(f_{c d}, E_{\mathrm{c}}\right)$; longitudinal and transverse reinforcement $\left(E_{s}, f_{y w d}, A_{s}, A_{s w}, s\right)$.

Bearing capacity of the corbel under the shear of the compressed zone under an inclined crack is equal to

$$
V_{R d}=\frac{f_{c d} b d n\left(0.5 \varphi_{1} l_{\text {sup }} / c+\varphi_{2} \alpha_{s w}+\alpha_{s}\right)}{n-\varphi_{2} c / d}
$$

where $n=1-0.25 l_{\text {sup }} / c ; \varphi_{1}=\bar{\varphi}_{c 1} /\left(1+\bar{\varphi}_{c 1} \operatorname{tg} \alpha\right)$, here $\bar{\varphi}_{c 1}=0.75$ at the concrete class $\mathrm{C} 20 / 25$ and less and $\bar{\varphi}_{c 1}=0.75 f_{c, C 20 / 25} / f_{c}$ at the concrete class more C20/25, $\operatorname{tg} \alpha_{\mathrm{o}}=d / c ; \varphi_{2}=\operatorname{tg}\left(\alpha_{\mathrm{o}}-\gamma\right)$, where $\gamma=\operatorname{arctg} \bar{\varphi}_{c 1} ; \alpha_{s w}=\frac{f_{y w d} A_{s w}}{f_{c d} b s} ; \alpha_{s}=0.9 \sqrt{\frac{A_{s}}{b d}-3.5 \times 10^{-3}} \geq 0$.

Bearing capacity under the shear within a compressed strip

$$
V_{R d}=\alpha_{c, s} f_{c d} b l_{s u p}\left(1+\alpha_{s w}\right),
$$

where $\alpha_{c, s}=1-\frac{l_{1}}{d}+t \frac{A_{s}}{b d} \sin \theta$, here $t=1.5 \frac{E_{s} d}{E_{c} l}, l_{c}=l_{s u p} \sin \theta, \sin \theta=\sqrt{\frac{d^{2}}{d^{2}+l_{1}^{2}}} ; \alpha_{s w}=t \frac{A_{s w}}{b d}$.

\section{Conclusions}

There is a need to create a sufficiently general methodology for calculating the bearing capacity of concrete and reinforced concrete elements under the shear that would cover various cases of failure and allow obtaining effective structural solutions.

In reinforced concrete corbels, the shear is realized at failure along the whole section, close to the normal, in a compressed zone under an inclined crack, within the inclined strip. 
It is proposed to use the mathematical apparatus of plasticity theory as the basis of the determining methods of bearing capacity of reinforced concrete corbels. In this case, concrete is considered as a rigid-plastic body, a variational method using the virtual velocities principle and the characteristic lines method is used. Plastic deformations are considered to be localized in thin layers on the failure surface. The ultimate load corresponds to the plastic deformation power minimum.

\section{References}

1. Layla A. Gh. Yassin, Eyad K. Sayhood, Qais Abdul Majeed Hasan, JMES, 2, 180-205, (2015)

2. D. L. Araújo, A. P. Silva Neto, F. A. Lobo, M. K. El Debs, IBRACON Structural and Materials Journal, 9(3), 435-470, (2016)

3. R. M. F. Canha, D. A. Kuchma, M. K. El Debs, R. A. Souza, Engineering Structures, 74, 130-144, (2014)

4. M. Lachowicz, K. Nagrodzka-Godycka, Engineering Structures, 108, 1-11, (2016)

5. L. O. Doroshkevych, B. Iu. Maksymovych, Mizhvidomchyi nauk.-tekhn. zb. nauk. prats (budivnytstvo), Kyiv, 59(1), 57-63, (2003)

6. V. Pohribnyi, O. Dovzhenko, L. Karabash, I. Usenko, Web of Conferences, 116, 02026, (2017)

7. L. B. Kriz, C. H. Raths, Journal of the Prestressed Concrete Institute, 10(1), 16-61, (1965)

8. O. Dovzhenko, V. Pohribnyi, I. Yurko, I. Shostak, Web of Conferences, 116, 02011, (2017)

9. O. Dovzhenko, V. Pohribnyi, L. Karabash, Journal of Engineering \& Technology (UAE), 7 (3.2), 354-359, (2018)

10. V. L. Kolmogorov, Mehanika obrabotki metallov davleniem, Moskow, 688, (1986)

11. V. P. Mitrofanov, Stroitelnaya mehanika i raschet sooruzheniy, Moskow, 6, 23-28, (1990)

12. G. A. Geniev, V. N. Kissyuk, G. A. Tyupin, Teoriya plastichnosti betona $i$ zhelezobetona, Moskow, 316, (1974)

13. O. A. Dovzhenko, V. V. Pogrebnoy, Ju. V. Chursa, Promyshlennoe i grazhdanskoe stroitel'stvo, Moscou, 2, 70-74, (2017)

14. O. A. Dovzhenko, V. V. Pohribnyi, L. V. Karabash, Science \& Technique, 17(2), 146-156, (2018)

15. O. Dovzhenko, V. Pogrebnyi, I. Yurko, News NAS RK. Series of geology and technical science, 2 (428), 212-219, (2018)

16. V. Pohribnyi, O. Dovzhenko, O. Maliovana, International Journal of Engineering and Technology(UAE), 7 (3.2), 19-26, (2018) 